\title{
Lymph Node Efferent Vessel
}

National Cancer Institute

\section{Source}

National Cancer Institute. Lymph Node Efferent Vessel. NCI Thesaurus. Code C33030.

Lymphatic vessels that transport filtered lymph out of lymph nodes. 